\title{
COMPARATIVE STUDY OF NON-LINEAR SIMULATIONS OF A REINFORCED CONCRETE SLENDER COLUMN USING FINITE ELEMENT METHOD AND P-DELTA
}

\author{
Régis Marciano de Souza \\ Federal Institute of Education, Science and Technology of the South of Minas Gerais (IFSULDEMINAS), Civil \\ Engineering Dept., End. Avenida Maria da Conceição Santos, 900, Parque Real, ZIP Code 37550-000, Pouso \\ Alegre-MG, Brazil \\ Corresponding author: regis.souza@ifsuldeminas.edu.br
}

\section{Ricardo Rodrigues Magalhães}

Federal University of Lavras (UFLA), Engineering Dept., P.O. Box 3037, ZIP Code 37200-000, Lavras-MG, Brazil

\author{
Ednilton Tavares de Andrade \\ Federal University of Lavras (UFLA), Engineering Dept., P.O. Box 3037, ZIP Code 37200-000, Lavras-MG, Brazil
}

\begin{abstract}
This paper analyzes the non-linear geometric behavior of reinforced concrete slender columns. This approach is due to the fact that there is a tendency to reinforced concrete slender constructions, which may have significant second order effects. This research aimed at comparing different formulations for the analysis of non-linear behavior of reinforced concrete slender columns by comparing results from simulated problem (slender column with ten load scenarios) between the Finite Element Method (FEM) and the Iterative Process P-DELTA(P- $\Delta)$. Numeric results revealed that the Iterative Process $\mathrm{P}-\Delta$ presented different results from FEM and that the second order effects are significant for reinforced concrete slender column problems.
\end{abstract}

Index terms: Reinforced concrete columns, geometric non-linearity, second-order effects.

Received: July, 30, 2018 - Accepted: December, 6, 2018

\section{INTRODUCTION}

In Brazil, as in many other countries, concrete plays an important role in construction, being the main and most consumed building material in the world. Two of the most developed and powerful societies, the United States and Canada, consider the investment in studies about concrete structures as one of the most important investments in science and technology to obtain and keep quality of life for their people and the leadership of their industrial parks (Helene and Andrade, 2010). According to NBR-6118 (ABNT, 2014), concrete elements are those which structural behavior depends on the adherence between the concrete and the armor, and to which initial armor elongations are not applied before such adherence.

The search for reinforced concrete slender constructions has boosted advancements in the area of structural engineering; one of these advancements is related to the study of non-linear behavior in structure. According to Delalibera et al. (2014), as slenderer the structure, greater is the need for analysis of second-order effects. According to Reis and Camotim (2012); Carvalho and Pinheiro (2013), column slenderness is defined by Equation 1 .

$\lambda=\frac{L_{e}}{i}$

where $\lambda$ is the slenderness ratio of the part with respect to axis $x$ or $y$ (columns are rated slender when $\lambda$ is higher than 90 and lower than 140); Le is the length of the buckling towards $x$ or $y$ and $i$ is the radius of gyration on $x$ or $y$.

Peres, Penna and Pitangueira (2014) highlight that the development of Finite Element Method (FEM) among other methods for non-linear structure analysis is a viable and widely spread alternative which allows a lot of structures modeling from different materials affected by many requests and restrictions. According to Cook et al. (1974), in structural mechanics, nonlinearity may be classified as material, geometric, 
or contact. The problems in these categories are non-linear because stiffness and other loads are functions of displacement or deformations. According to Carvalho and Pinheiro (2013), at the geometric analysis of a non-linearity structure, the purpose is to determine the internal actions, considering second order effects (deformed position). Second order effects arise from the geometric change in structures due to the incidence of external loads. According to Parente Junior et al. (2014), the geometric nonlinear analysis may be performed by using Lagragian or co-rotating formulations.

According to Cook et al. (1974), for solving these kinds of structural problems, the use of FEM with an incremental-iterative process is an alternative, where the balance configuration of the structure is performed by an external load. Newton-Raphson algorithm is commonly used in modeled non-linear problems in finite elements. Alves Filho (2012) stated that NewtonRaphson method is one of the most important methods to understand iterative strategies. Other numeric methods may be used in the process of computational implementation routine for a non-linear analysis such as: standard NewtonRaphson method, modified Newton-Raphson method, Arc-Length Method, Elliptic Arc-Length technique, Spherical arc-length technique, cylindrical arc-length technique, linearized arclength technique, among others.

According to Reis and Camotim (2012), another way to solve these problems is the use of Iterative Process P-DELTA(P- $\Delta)$, where the equations are written based on the nondeformed configuration of the structure and geometric non-linearity effects are incorporated indirectly and iteratively. In this kind of analysis, a non-linear problem is effectively solved by using successive linear problems. Delalibera et al. (2014) pointed out the importance using an analytical calculation process for second-order analyses in symmetrical and rectangular models without geometric alteration of pavements.

\section{FEM Background}

FEM is a numeric technique for analyzing in approximate way the behavior of problems governed by physical phenomena that can be expressed in partial or ordinary differential equations. Belytschko and Fish (2009) states that many phenomena in engineering and science can be described in terms of differential equations. In general, solving these equations by means of classical analytical methods for irregular geometries is almost impossible. FEM is a numerical approximation tool using differential equations can be solved in an approximate way. An application of this method in Structural Engineering is the study of linear and nonlinear elastic behavior of structures by means of computer simulations. Clough (1960) was the first author to use the term Finite Elements. Turner et al. (1960) considered the effect of large deformations in the analysis of structures subjected to external loads and temperature effects. Archer (1965) expanded FEM approaches for dynamic analysis. Argyris and Kelsey (1960) presented fundamental principles of matrix analysis of structural methods, including the effects of temperatures and the consideration of a nonlinear relationship between stressdeformation, clearly revealing the duality between the method of displacements and the method of loads.

According to Soriano (2009), FEM started from the arbitrary of simple laws (usually polynomial) for the primary dependent variables in subdomains called finite elements, replacing the exact laws of mathematical model solution (which are unknown) and to have continuity in the interfaces of elements, in most developments. These elements are interconnected by means of nodal points in their contours and since these laws are arbitrated as a function of nodal parameters, the infinite points of the continuous mathematical model are replaced by a finite number of points, which is called the discretization process of the continuous mathematical model. In a mathematical condition that ensures approximate solution that converges to the solution of the original mathematical model, while the elements size is reduced or the order of the laws arbitrated for variables is increased. This mathematical model, which is already approximate to the physical system, has its behavior determined with additional approximation through a FEM discrete model (Figure 1). 


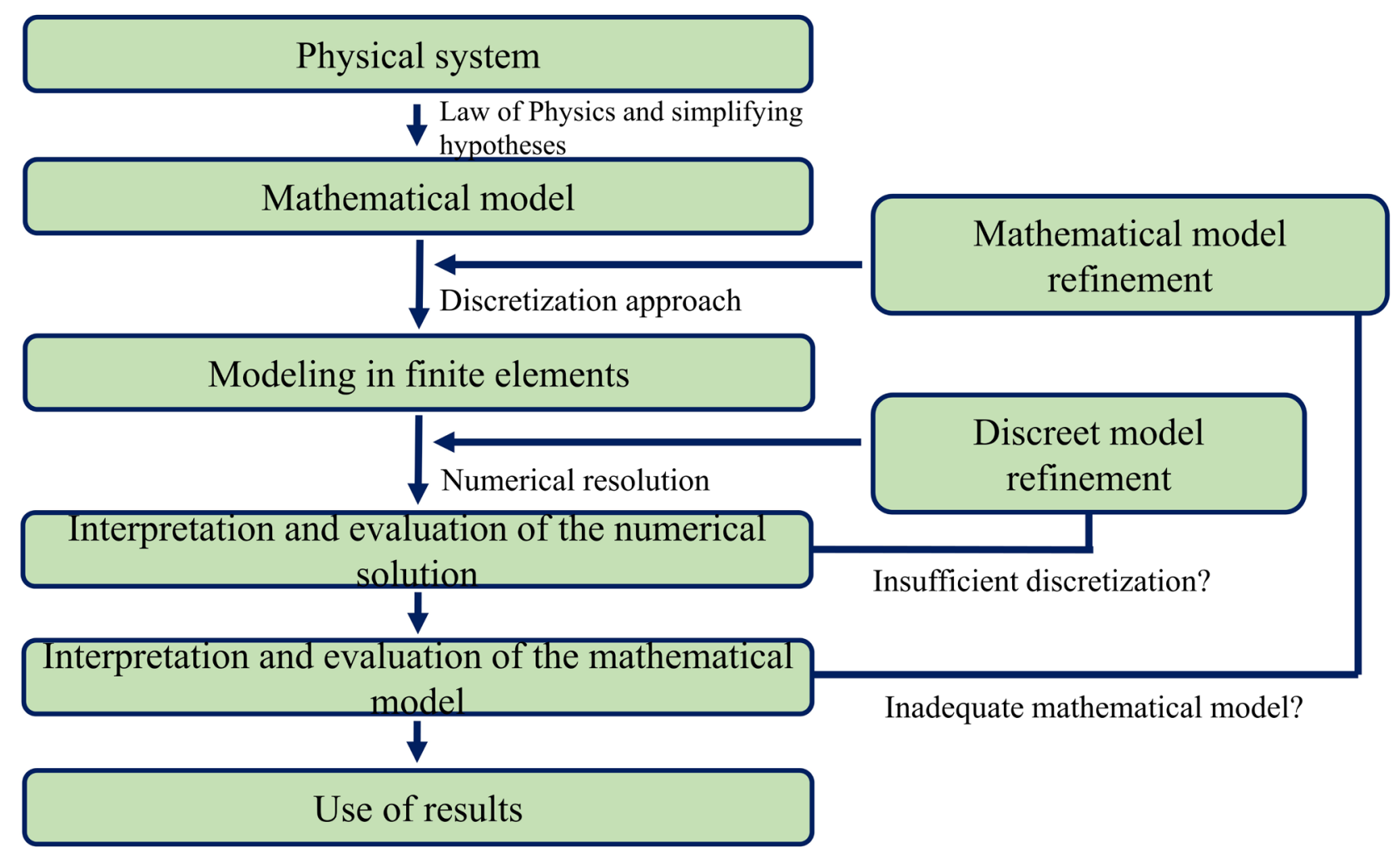

Figure 1: Generic context of FEM.

In the Finite Element modeling, mesh construction is an extremely important step. This set of discrete elements interconnected bynodes can contribute and ensure good results for the simulations. A procedure of successive mesh refinement can ensure the convergence of the numerical solution to a correct result. Cook et al. (1974) and Brandão et al. (2009) presented methods of automatic refinement of finite element meshes, also called adaptive methods, trying to make errors distribution over the whole mesh.

According to Soriano and Lima (2003) and Soriano (2009), automatic mesh refinement, which is self-adaptive, is a function of a parameter or level convergence specified by the user. It is selective in order to act primarily in regions that lack refinement until an error of discretization is obtained evenly distributed in the entire mesh. These adaptive refinement strategies can be basically divided into three types: $h, p$ and $r$. Cook et al. (1974) and Brandão et al. (2009) stated that $\mathrm{p}$ and $\mathrm{h}$ types refinements are different ways to increase the number of the model's degree of freedom. In the h-type refinement, the degree of the polynomials used (same type of element) is not changed, the refinement is performed by the division from mesh discrete elements. In the p-type refinement, there is an increase in the degree $(p)$ of the polynomial seeking to enrich the solution space. Another refinement form is the r-type, where refinement is accomplished by repositioning nodal points of the mesh, thus improving the distribution of errors. For Soriano (2009), the combination of $\mathrm{p}$ and $\mathrm{h}$ types refinements is called the hp-type refinement. For Szabo and Babuâška (1991), the convergences results of $h, p$ or hp types refinements, are called $h, p$ or hp convergence.

\section{Formulation for Linear Analysis}

According to Soriano (2009), FEM formulations is performed by direct variation form from Rayleigh-Ritz Method or through the weak form from the Galerkin Method. The variation approach is more classical than Galerkin's; however, the latter has the advantage of being more general than the former. Both, in the case of physical system governed by functional, provide the same results. To obtain the system of equilibrium equations of an element, one must follow the steps presented in Figure 2. 


\section{Displacement field arbitration of the element in the means of interpolation of its} nodal displacements $\rightarrow$ Matrix $\mathbf{N}$

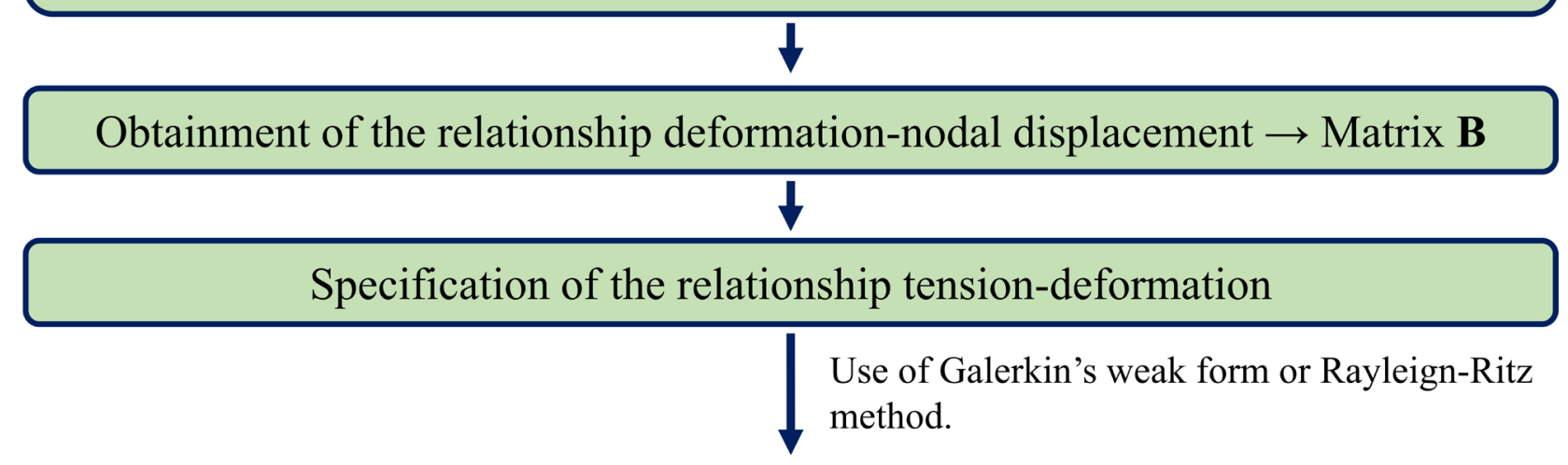

\section{Obtainment of the equilibrium equiation system that relates nodal forces with nodal displacements, $[\mathbf{K}]^{(\mathrm{e})}\{\mathbf{u}\}^{(\mathrm{e})}=\{\mathbf{F}\}^{(\mathrm{e})}$}

Figure 2: Steps to obtain a system of equations of an element (adapted from Soriano, 2009).

Cook et al. (1974) defined the global system of algebraic equilibrium equations for a structure with $n$ elements, Equation 2.

$$
[K]=\sum_{e=1}^{n}\left[K_{i j}^{e}\right]
$$

where $[K]$ is the global stiffness matrix by combining the stiffness matrices of the elements $\left[K_{i j}^{e}\right]$ in a systematic assembly process.

The vector of nodal loads is defined by Equations 3 and 4.

$$
\begin{aligned}
& \{F\}=\{Q\}+\sum_{e=1}^{n}\left\{R_{i}^{e}\right\} \\
& \{F\}=[K]\{u\}
\end{aligned}
$$

where $\{F\}$ is the global vector of nodal forces, $\{Q\}$ is the vector of external forces applied to the nodes, $\left\{R_{i}^{e}\right\}$ is the vector of nodal forces applied in the structure and $\{u\}$ is the nodal displacement vector.

Soriano (2009) presented a systematic process for the determination of the global stiffness matrix $[K]$ of the structure in non-time-dependent linear behavior. In this process, the stiffness matrix of the element is defined in terms of its nodal parameters. The element stiffness coefficients are transformed from the local reference system to the global reference system.

MoreinformationonFEMinstructuralanalysis can be found in the references (Zienkiewicz and Cheung, 1967; Cook et al., 1974; Segerlind, 1984; Szabo and Babuâška, 1991; Reddy, 1993; Oñate, 1995; Assan, 2003; Belytschko and Fish, 2009; Soriano, 2009; Eloy, 2011).

\section{Formulation for Non-Linear Analysis}

Plumbridge, Matela and Westwater (2003) presented the formulations for linear and nonlinear analysis by FEM and compared the main differences between them. Bueno and Loriggio (2016) point out that the choice of the most appropriate procedure to be used depends on several factors, such as the magnitude of the displacements and rotations in the structure, the level of normal working forces, the sensitivity of the structure to second order effects, among others.

According to Alves Filho (2012), the NewtonRaphson method for incremental/iterative analysis is one of the most widespread nonlinear analysis of structural systems by using FEM and consists of the fractional application of the load, called charge increment, cumulatively throughout the analysis until the loading is completely applied and the algebraic equilibrium 
equations are solved by an iterative process. Equation 4 can be rewritten for non-linear problems in Equations 5-7, corresponding to the n - 1 increment (Cook et al.,1974; Reddy, 1993; Bathe, 2014).

$$
\begin{aligned}
& \{F\}_{\mathrm{n}}-\{P\}_{\mathrm{n}-1}=\left[K_{T}\right]_{\mathrm{n}-1}\{\Delta u\}_{\mathrm{n}} \\
& \{u\}_{\mathrm{n}}=\{u\}_{\mathrm{n}-1}+\{\Delta u\}_{\mathrm{n}} \\
& {\left[K_{T}\right]=\frac{\{d P\}}{\{d \Delta u\}}}
\end{aligned}
$$

where $\left[K_{T}\right]$ is the tangent stiffness matrix defined and $n$ are the displacements increment; $\{P\}_{n-1}$ is the vector equivalent nodal loads that depends on the displacement $\{u\}_{\mathrm{n}}$. These corrective cycles continue until the residual loads $\left(\{F\} n-\{P\}_{\mathrm{n}-1}\right)$ and the incremental displacements $\Delta u$ are sufficiently small.

Sindel and Tezcan (1996) presented more details on the formulation of tangent stiffness matrix $\left[K_{T}\right]$. Alves Filho (2012), Bathe (2014), Bhavikatti (2005), Parente Junior et al. (2014), Plumbridge, Matela and Westwater (2003) and Reis and Camotim (2012) presented another way of expressing the tangent stiffness matrix $\left[K_{T}\right]$ (Equation 7). This tangent stiffness matrix $\left[K_{T}\right]$ can be decomposed into two plots $\left[K_{G}\right]$ e $\left[K_{E}\right]$,being the first plot relative to geometric nonlinear behavior and the second one referring to linear elastic behavior, Equation 8 .

$$
\left[K_{T}\right]=\left[K_{G}\right]+\left[K_{E}\right]
$$

where $\left[K_{E}\right]$ is the elastic stiffness matrix and $\left[K_{G}\right]$ is the geometric stiffness matrix.

Vellasco et al. (2014), presented the concepts of nonlinear analysis of structures and stated that the tangent stiffness matrix $\left[K_{T}\right]$ must be able to relate, precisely, the displacement and load increments; the accuracy of the method depends on the accuracy of the tangent stiffness and the size of the loading steps.

According to Alves Filho (2012), the NewtonRaphson method has two definitions, which are presented as standard Newton-Raphson method and Newton-Raphson modified. In the first one, the tangent stiffness matrix is updated in each iteration and in the second the matrix of tangent stiffness is updated only once at the beginning of each increment. Figure 3 presented the relationship between load $(\mathrm{P})$ and displacement $(\mathrm{u})$ in a non-linear analysis by using the Newton-Raphson method standard Figure 3 (a) and modified, Figure 3 (b). In Figure 3 (a), the tangent stiffness matrix $\left[K_{T}\right]$ is updated at each iteration, for each force increment P. In Figure 3 (b), the tangent stiffness matrix $\left[K_{T}\right]$ is constant and updated only once at the beginning of each force increment $P$.

In the Newton-Raphson method, the iterative cycle of successive approximations seeks to drive the numerical response to a minimum error. According to Cook et al. (1974) and Zienkiewicz and Taylor (2000), equilibrium iterations can cease when the approximate results meet the convergence criteria. Two convergence criteria can be used, the convergence of displacements and the convergence of forces. For Zienkiewicz and Taylor (2000), errors can occur if only one of these types of verification is used.

\section{Iterative Process P- $\Delta$}

According to Gaiotti and Smith (1989); Delalibera et al. (2014), at each iteration, a new fictitious lateral load $\left(H_{i}^{\prime}\right)$ of a stage $i$ is obtained. This procedure is repeated until reaching the equilibrium position and can be applied in multi-storey buildings. Where the dummy shear forces $V^{\prime}{ }_{i}$ can be obtained by Equation 9 and the fictitious side loads $H^{\prime}{ }_{i}$ by Equation 10.

$$
\begin{aligned}
& V_{i}^{\prime}=\frac{\sum P_{i}}{h_{i}}\left(\Delta_{i+1}-\Delta_{i}\right) \\
& H_{i}^{\prime}=V_{i-1}^{\prime}-V_{i}^{\prime}
\end{aligned}
$$

where $H_{i}^{\prime}$ is the dummy side load of a floor i, $V^{\prime}{ }_{i}$ is the fictitious shear stress of a floor $i, \mathrm{P}$ are the vertical forces applied at each level $i, h$ is the difference between the levels $\mathrm{i}$ (height), $\mathrm{D}$ is the horizontal displacement of a stage $i$. 

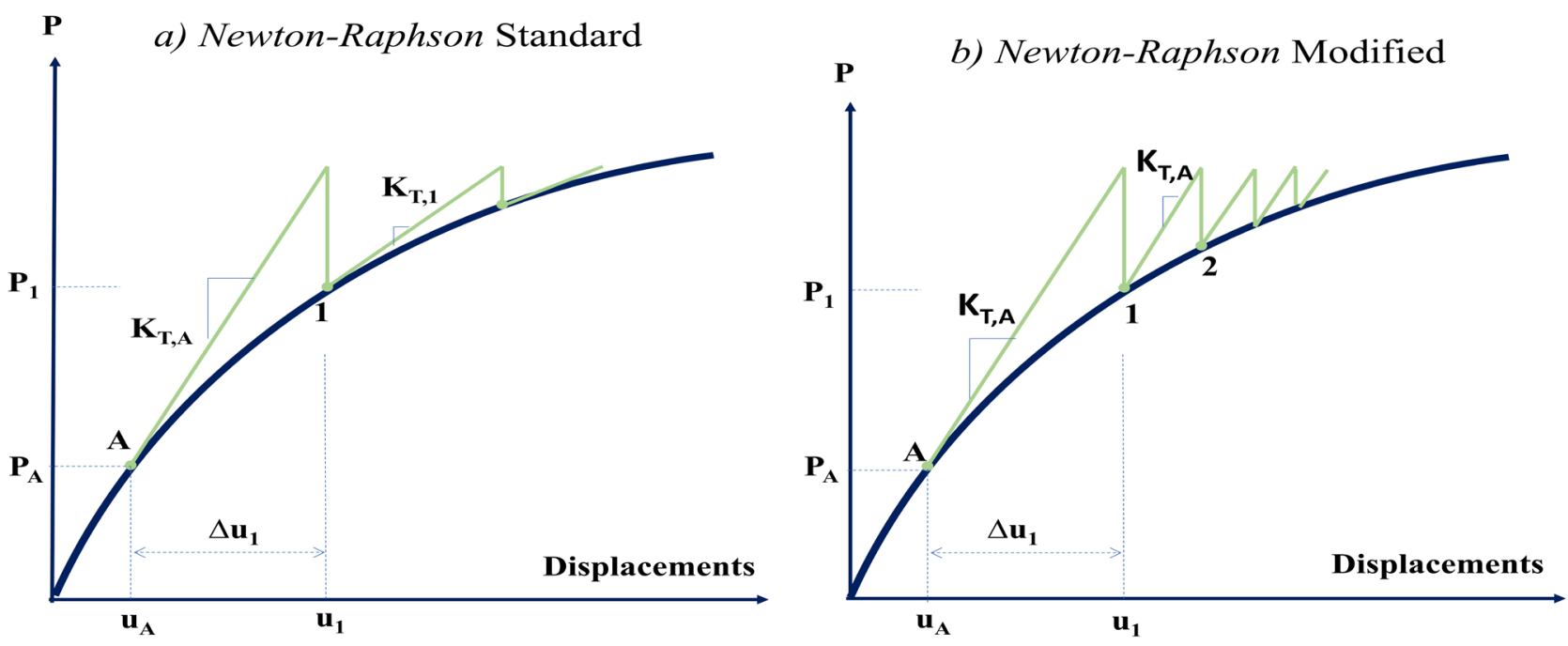

Figure 3: Standard (a) and modified (b) Newton-Raphson Methods (adapted from COOK et al.(1974).

Delalibera et al. (2014) emphasized the importance of using an analytical calculation process for second order analysis in symmetric and rectangular models without changing the pavements geometry, since they provide a coherent response to the reality of the structure behavior, and considered the results more conservative than computational numerical computation.

For Gaiotti and Smith (1989), the iterative process $\mathrm{P}-\Delta$ is repeated for each force increment based on the displacement values, until the value of the previous iteration does not change significantly. Normally, two or three iterations are sufficient, if the results do not converge after five iterations, the structure can be classified as unstable.

\section{MATERIAL AND METHODS}

In terms of a model considering a non-linear geometric behavior without buckling effects, it is proposed a column with 5 meters height and square cross-section of $0.16 \mathrm{~m}^{2}$, moment of inertia $2.133333 \times 10^{-3} \mathrm{~m}^{4}$ in the $\mathrm{x}$ and $\mathrm{y}$ axes. A buckling length $\mathrm{Le}=10 \mathrm{~m}(\mathrm{Le}=2 \mathrm{~L})$ and critical load was defined as proposed by (Carvalho and Pinheiro, 2013). According to Carvalho and Pinheiro (2013), a column with these geometric characteristics can be classified as having average slenderness, as a function of the slenderness index (Equation 1). As the slenderness ratio $\lambda=$ 86.6, a value close to the limit characterizes the slender structure. For this reason it was chosen in this case, the classification of slender.
In relation to the conditions of clamping and geometry, some simplifying hypotheses were adopted for the model conception:

a) It was considered a bar model to study the behavior of the proposed problem;

b) The degrees of freedom are restricted at the base with no prescribed displacements;

c) The degrees of freedom of the upper border are free without any restriction movements;

d) The structure is in stable equilibrium.

The proposed model is a reinforced concrete column, with a characteristic resistance $f c k$ of 35 $\mathrm{MPa}$ and Poisson coefficient of 0.2. Regarding the material behavior, some simplifying hypotheses were adopted:

a) The cross section remains flat after the deformation beginning until the final equilibrium in the deformed position;

b) Perfect adhesion between concrete and steel; the specific deformation of a steel bar was considered equal to the specific deformation of the adjacent concrete;

c) A gneiss aggregate is used, which allows the estimation of the modulus of elasticity through the formulation presented by NBR-6118 (ABNT, 2014), secant longitudinal elastic modulus of $E$ $=26504037.43 \mathrm{kN} / \mathrm{m}$.

d) The non-linearity of the reinforced concrete material was considered as recommended by NBR-6118 (ABNT, 2014) by reducing the stiffness of the structural element $(0.8 \mathrm{EI})$;

e) Reinforced concrete was considered isotropic and homogeneous; 
f) The cross-sectional area of the longitudinal compression reinforcement is equal to the cross-sectional area of the longitudinal tensile reinforcement.

The acting external loads are represented by the loads $\mathrm{H}$ and $\mathrm{P}$, since $\mathrm{H}$ is the load horizontal position located at the top of the column $(40 \mathrm{kN})$ and $\mathrm{P}$ the vertical load applied at the top of the column $(8000 \mathrm{kN})$.

Some simplifying hypotheses were also adopted for the actions study:

a) External loads applied are static and clamped, other external effects were disregarded;

b) The effects of concrete deformation over time were disregarded;

c) The thermal effects and the retraction of the concrete were disregarded;

d) The loads are applied in the geometric center of the column cross section without eccentricities; e) The stability of the structural model was guaranteed by establishing a vertical load value $\mathrm{P}$ less than the critical load $\mathrm{Pcr}=55804.64 \mathrm{kN}$;

f) The total vertical load $\mathrm{P}$ was divided into 10 parts and applied incrementally, each increment with a value corresponding to $10 \%$ of the load $\mathrm{P}$. The first analysis was performed for a value of $\mathrm{P} 1=0.10 \mathrm{P}$, the second analysis was performed with a value of $\mathrm{P} 2=0.20 \mathrm{P}$, and so on, up to the force P.
Non-linear analysis by the iterative process P- $\Delta$.

The Iterative Process $\mathrm{P}-\Delta$ is inserted in different geometric non-linear structural analysis algorithms. In this study, a computational routine was developed on MATLAB in order to implement the iterative process P- $\Delta$ for $n$ analyzes (Figure 4).

\section{Nonlinear geometric analysis by using FEM}

Nonlinear geometric analysis was performed by ABAQUS software. The first step was the model generation: a 2D Planar, Type: Deformable, Base Feature: Wire Planar. The geometric representation was possible using the Create Lines: Connected tool, with base coordinates $\left(X_{\text {Base }}=0 \mathrm{~m} ; \mathrm{Y}_{\text {Base }}=0 \mathrm{~m}\right)$ and top $\left(X_{\text {Topo }}=0 \mathrm{~m} ; Y_{\text {Topo }}=5 \mathrm{~m}\right)$.

The next step was the definition of the properties of Elastic Type Isotropic materials and Young's Modulus and Poisson Ration values. The cross-sections were defined as Beam-type and assignment of these properties to the element in Assign Section. The Assembly module was used to Create Instances from Parts and set assembly (template) to a viable referential position analysis. The characteristics of the analysis process were defined in the

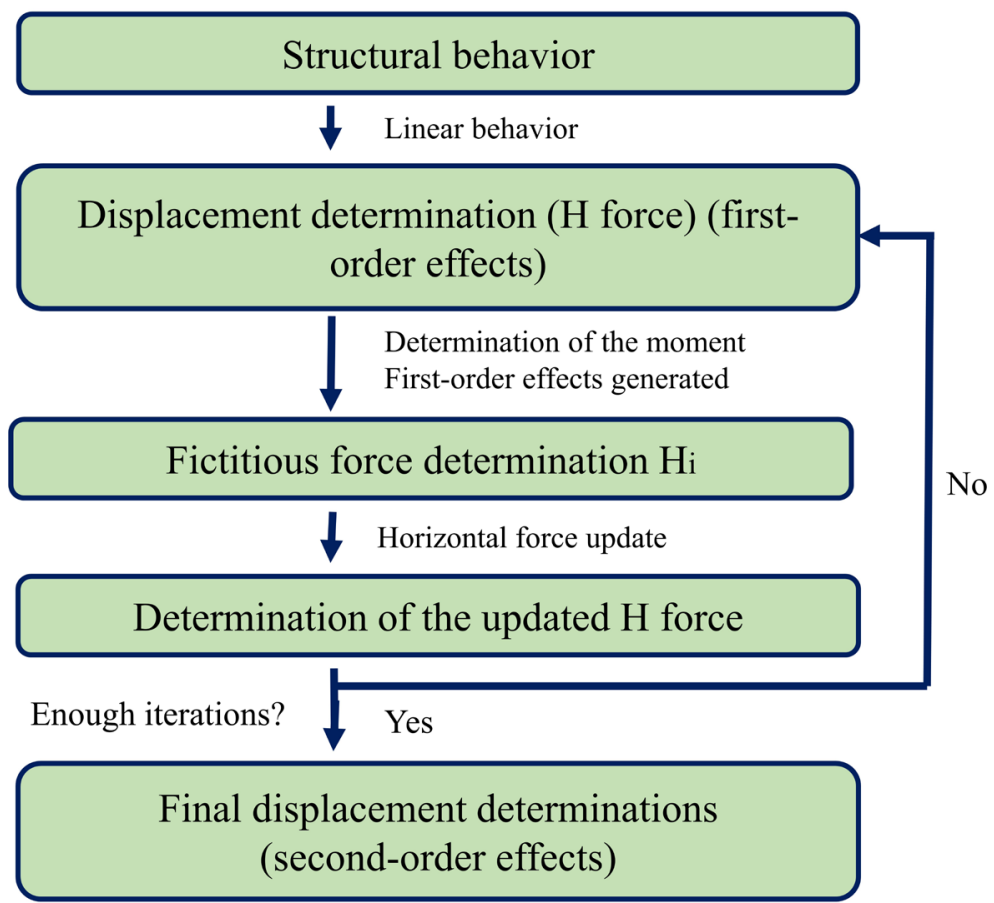

Figure 4: Simplified scheme of the Iterative Process P- $\Delta$. 
Step, Type Static/-General module, with consideration of NLGeom (Geometric Nonlinearity), Incrementation Automatic, resolution of equations by Method Direct, with Solution Technique Full Newton. The Interaction module was not used; this model had no iteration with other bodies.

The Load module was used to apply the external loads $\mathrm{Pn}$ and $\mathrm{H}$, for the $\mathrm{n}$ analyzes, in Create Load; and for defining boundary conditions in Create Boundary Condition. In the Mesh module, in Assign Element Type, the characteristics of the elements used in the numerical simulations were defined. Elements type Beam were defined in Family, with Quadratic order established in Geometric Order. These elements are identified in ABAQUS by B22 (A 3-node quadratic beam in a plane).

The Mesh module was also used to define the number of elements. It was chosen the by Number method, with manual refinement of type h (Figure 5). According to Soriano (2009), the type $h$ refinement can be done by increasing the number of elements, starting with the discretization of the continuous medium problem in a simple mesh, and gradually this model is refined until results with the desired accuracy. The Mesh Part tool was used to create the mesh with 25 finite elements (post refining).

In the Jobs processing module, which is part of Analysis, a Create Job processing job was created. In this step, after Create Job and Submit, the visualization and monitoring of the numerical simulation process was performed. The postprocessing was performed in the Visualization module, where the graphical representation, treatment and selection of the data of the nonlinear analysis of second order effects were performed. These results were presented in a quantitative way, in MATLAB software, in a graph that represented the equilibrium trajectory of the proposed model. More details on FEM applications with ABAQUS software can be found in (Belytschko and Fish, 2009; Campilho, 2012; Khennane, 2013).

\section{Comparative Analysis}

The MATLAB software was used for basic statistical analysis of the numerical simulations results. A comparative study was carried out in order to evaluate the results of the second-order effects of the slender column model on reinforced concrete between the two distinct formulations: Iterative Process P- $\Delta$ and Numerical Modeling in Finite Elements. The absolute error between the simulations from the ten scenarios were obtained by Equation 11 and the relative errors by Equation 12 .

$E_{\mathrm{A}}=\left|U_{x}^{2 M E F}-U_{x}^{2 P-\Delta}\right|$

$E_{R}=\left|\frac{U_{x}^{2 M E F}-U_{x}^{2 P-\Delta}}{U_{x}^{2 M E F}}\right|$

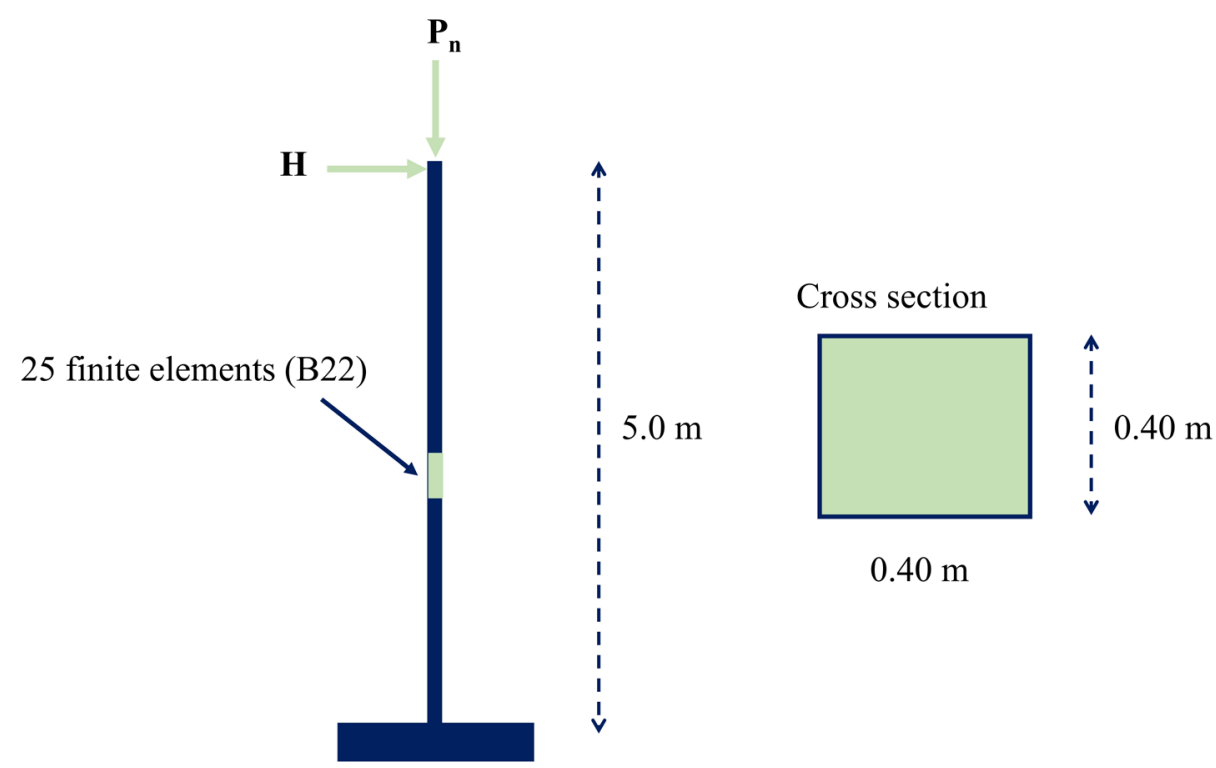

Figure 5: Finite Element Model. 
where $E_{A}$ is the absolute error between the two simulations (in absolute value), $E_{R}$ is the relative error between the two simulations with respect to the simulation from FEM (also in absolute value), $U_{x}^{2 M E F}$ is displacement (second order effect) in the horizontal axis (x) at the top of the column from MEF, $U_{x}^{2 P-\Delta}$ is displacement (second order effect) in the horizontal axis ( $x$ ) at the top of the column from the iterative process $\mathrm{P}-\Delta$.

\section{RESULTS AND DISCUSSION}

The Iterative Process P- $\Delta$ in the proposed scenarios (ten analysis) were performed. Considering iterative cycles to determine the fictitious loads and corresponding displacements, the cycle was interrupted when the displacements reached a null value with precision of four decimal places. The final displacements, called second order effects $U_{x}^{2 P-\Delta}$, the sum of displacements of each iteration from the iterative process were presented in Table 1.

Results from numerical simulations, displacements of the second-order theory $U_{x}^{2 M E F}$ (non-linear) by using FEM from the ten proposed scenarios are also presented in Table 1.

For the numerical simulations by the P- $\Delta$ Iterative Process of the suggested slender column, the number of iterations increased with increasing loads. The first eight analyzes reached equilibrium by the iterative process. The P- $\Delta$ Iterative Process did not reach equilibrium in the last two analyzes. Results from numerical simulations confirmed that with vertical loads higher than $7200 \mathrm{kN}$ was not possible to reach equilibrium due to the significant contributions of these vertical loads to the second order bending moments.

Results from numerical simulations supported by FEM are compared to the results of the Iterative Process $\mathrm{P}-\Delta$, in a statistical analysis of the absolute errors $E_{A}$ and relative $E_{R}$ are shown in Table 1.

It is observed in Table 1 that the difference between the values begins to increase with the increase of the vertical load $\mathrm{P}$, with maximum discrepancy in the scenario with $\mathrm{P}=5600 \mathrm{kN}$. Also in Table 1, it is presented the absolute errors $E_{A}$ and relative percentage $E_{R^{\prime}}$ being the eighth analysis presented the largest relative error $E_{R}$ percentage of $166 \%$.

According to Gaiotti and Smith (1989), two or three iterations are usually sufficient, if the results do not converge after five iterations, the structure can be classified as unstable. In this work, the simulations performed reached iterative cycles of 4 to 111 iterations, confirming that the larger the number of iterations, greater the differences between the second order effects determination processes. In this case, the structure has reached equilibrium in the Iterative Process P- $\Delta$, these results may differ significantly from the results of numerical simulations by MEF.

Tabarelli et al. (2002), analyzed the geometric nonlinear behavior of multi-story buildings in steel and compared the application of the dummy load method with FEM simulations (ANSYS computational simulation), as a response a 3\% error between both applications. This result is compatible with the results of the analyzes carried out in the first scenario proposed in this research.

Table 1: Simulation data on FEM and P- $\Delta$.

\begin{tabular}{ccccccc}
\hline Analyzes & $\begin{array}{c}\mathrm{P}_{\mathrm{n}} \\
{[\mathrm{kN}]}\end{array}$ & $\begin{array}{c}\mathrm{H} \\
{[\mathrm{kN}]}\end{array}$ & $\begin{array}{c}\mathrm{MEF} U_{x}^{2} \\
{[\mathrm{~m}]}\end{array}$ & $\begin{array}{c}\mathrm{P}-\Delta U_{x}^{2} \\
{[\mathrm{~m}]}\end{array}$ & $\begin{array}{c}\mathrm{E}_{\mathrm{A}} \\
{[\mathrm{m}]}\end{array}$ & $\begin{array}{c}\mathrm{E}_{\mathrm{R}} \\
{[\%]}\end{array}$ \\
\hline $1^{\mathrm{a}}$ & 800.00 & 40.00 & 0.0345 & 0.0336 & 0.0009 & 2.7 \\
$2^{\mathrm{a}}$ & 1600.00 & 40.00 & 0.0413 & 0.0387 & 0.0026 & 6.3 \\
$3^{\mathrm{a}}$ & 2400.00 & 40.00 & 0.0516 & 0.0458 & 0.0058 & 11.2 \\
$4^{\mathrm{a}}$ & 3200.00 & 40.00 & 0.0689 & 0.0560 & 0.0128 & 18.6 \\
$5^{\mathrm{a}}$ & 4000.00 & 40.00 & 0.1018 & 0.0721 & 0.0297 & 29.1 \\
$6^{\mathrm{a}}$ & 4800.00 & 40.00 & 0.1888 & 0.1012 & 0.0876 & 46.4 \\
$7^{\mathrm{a}}$ & 5600.00 & 40.00 & 1.3780 & 0.1695 & 1.2085 & 87.7 \\
$8^{\mathrm{a}}$ & 6400.00 & 40.00 & 0.1961 & 0.5215 & 0.3254 & 166.6 \\
$9^{\mathrm{a}}$ & 7200.00 & 40.00 & 0.0993 & - & - & - \\
$10^{\mathrm{a}}$ & 8000.00 & 40.00 & 0.0664 & - & -
\end{tabular}


Comparative tests between numerical simulations and numerical simulations showed the feasibility of using numerical simulations by using FEM, among these works which is highlighted in (Wood and Zienkiewicz, 1977).

\section{CONCLUSIONS}

This paper showed that Iterative Process $\mathrm{P}-\Delta$ results were divergent from the numerical simulations by using MEF, reaching a relative error of $166 \%$. In this research, the iterative process proved to be impractical in high load situations, not reaching the deformed equilibrium situation in two scenarios. This process also presented extensive cycles of iterations, reaching up to 111 iterations, which significantly affects computational costs.

This research ratified the importance of the study of the formulations for nonlinear behavior analysis of slender columns in reinforced concrete. It is observed that the second order effects are significant in slender columns and that the results may differ depending on the type of formulation used.

In other hand, the analysis of the studied model from numerical simulations by using FEM presented reliable results, which can be used in decision making processes in engineering projects.

\section{REFERENCES}

ALVES FILHO, A. Elementos Finitos: A base da Tecnologia CAE análise não linear. 1. ed. São Paulo: Érica, 2012. 320p.

ARCHER, J. S. Consistent matrix formulations for structural analysis using finite-element techniques. AIAA Journal, 3(10): 1910-1918, 1965.

ARGYRIS, J. H.; KELSEY, S. Energy Theorems and Structural Analysis: A Generalised Discourse with Applications on Energy Principles of Structural Analysis Including the Effects of Temperature and Non-Linear Stress-Strain Relations. 1. Ed. London: Butterworths, 1960. 85p.

ASSAN, A. E. Método dos Elementos Finitos. 2. ed. São Paulo: Editora UNICAMP, 2003. 760p.
ASSOCIAÇÃO BRASILEIRA DE NORMAS TÉCNICAS. NBR 6118: Projeto de Estruturas de Concreto - Procedimento. Rio de Janeiro, 2014. 238p.

BATHE, K.-J. Finite Element Procedures. 2. ed. Watertown: Prentice Hall, Pearson Education, 2014. 1943p.

BELYTSCHKO, T.; FISH, J. Um primeiro curso em elementos finitos. 1. ed. Rio de Janeiro: LTC, 2009. 256p.

BHAVIKATTI, S. Finite element analysis. 1. ed. New Delhi: New Age International, 2005.324p.

BRANDÃO, D.; DE OLIVEIRA， S. L. G.; KISCHINHEVSKY, M. Finite-element nonconforming h-adaptive strategy based on Autonomous Leaves Graph. In: International Conference on Computational Science. Springer, Berlin, Heidelberg, 5544(56):570-579, 2009.

BUENO, J. R.; LORIGGIO, D. D. Analysis of second order effects: case study. Revista IBRACON de Estruturas e Materiais, 9(4):494-501, 2016.

CAMPILHO, R. D. S. G. Método de Elementos Finitos: Ferramenta para Análise Estrutural. 1. ed. Portugal: Publindústria, 2012. 205p.

CARVALHO, R. C.; PINHEIRO, L. M. Cálculo e Detalhamento de Estruturas Usuais de Concreto Armado. 1. ed. São Paulo: PINI, 2013. v. 2. 617p.

CLOUGH, R. The finite element method in plane stress analysis proceedings. In: ASCE Conference on Eletronic Computation, Pittsburgh, 8(1):345-378, 1960.

COOK, R. D. et al. Concepts and applications of finite element analysis. 4. ed. New Jersey: John Wiley \& Sons, 2003. 719p.

DELALIBERA, R. G. et al. Avaliação dos critérios para análise da estabilidade global em edifícios de concreto armado: estudo de caso. REECRevista Eletrônica de Engenharia Civil, 9(2):2436, 2014.

ELOY, L. Métodos dos Elementos Finitos em Análise de Estruturas. 1. ed. Rio de Janeiro: Elsevier Brasil, 2011. 273p. 
GAIOTTI, R.; SMITH, B.S. P-delta analysis of building structures. Journal of Structural Engineering, American Society of Civil Engineers, 115(4):755-770, 1989.

HELENE, P.; ANDRADE, T. Materiais de Construção Civil e Princípios de Ciência e Engenharia de Materiais. In: ISAIA, G. (Ed.). Concreto de Cimento Portland. São Paulo: IBRACON, 2010. v. 2, cap. 29, p. 945-984,.

KHENNANE, A. Introduction to Finite Element Analysis using MATLAB and ABAQUS. 1. ed. New York: CRC Press, 2013. 453p.

OÑATE, E. Cálculo de estructuras por el método de elementos finitos: análisis elástico lineal. 2. ed. Barcelona: Centro Internacional de Métodos Numéricos en Ingeniería, 1995. 838p.

PARENTE JUNIOR, E. et al. Material and geometric nonlinear analysis of reinforced concrete frames. Revista IBRACON de Estruturas e Materiais, 7(5):879-904, 2014.

PERES, L. M.;PENNA, S.S.;PITANGUEIRA, R. L. daS. Análise fisicamente não linear de pórticos de concreto armado. XI Simpósio de Mecânica Computacional e II Encontro Mineiro de Modelagem Computacional, 2014.

PLUMBRIDGE, W.; MATELA, R. J.; WESTWATER, A. Non-linear finite element analysis. In: Structural Integrity and Reliability in Electronics: Enhancing Performance in a Lead-Free Environment. Dordrecht: Springer Netherlands, 2003. cap. 17, p.305-318.

REDDY, J. N. An introduction to the finite element method. 2. ed. New York: McGraw-Hill, 1993. 684p.

REIS, A.; CAMOTIM, D. Estabilidade e Dimensionamento de Estruturas. Lisboa: Edições Orion, 2012. 688p.

SEGERLIND, L. J. Applied finite element analysis. 2. ed. New York: John Wiley \& Sons Inc, 1984. 427p.

SINDEL, Z.; TEZCAN, S. Tangent stiffness properties of finite elements. In: Computers and structures, Elsevier, 58(2):351-365, 1996.

SORIANO, H. L. Elementos finitos: formulação e aplicação na estática e dinâmica das estruturas. 1. ed. Rio de Janeiro: Ciência Moderna, 2009. 411p.
SORIANO, H.; LIMA, S. D. S. Método de Elementos Finitos em Análise de Estruturas. São Paulo: EDUSP, 2003. v. 48. 580p.

SZABO, B.; BABUÂŠKA, I. Finite Element Analysis. Canada: Wiley, 1991. 384p.

TABARELLI, A.; ARAÚJO, E. C. d.; PRESTES, J. A. S. Análise comparativa de sistemas verticais de estabilização e a influência do efeito p-delta no dimensionamento de edifícios de andares múltiplos em aço. Rem: Revista Escola de Minas, 55(4):251255, 2002.

TURNER, M. J. et al. Large deflections of structures subjected to heating and external loads. Journal of the Aerospace Sciences, 27(2):97-106, 1960.

VELLASCO, P. C. G. d. S. et al. Modelagem de Estruturas de Aço e Mistas. 1. ed. Rio de Janeiro - RJ: Elsevier, 2014. 335p.

WOOD, R.; ZIENKIEWICZ, O. Geometrically nonlinear finite element analysis of beams, frames, arches and axisymmetric shells. In: Computers and Structures, 7(6):725-735, 1977.

ZIENKIEWICZ, O. C.; TAYLOR, R. L. The finite element method: solid mechanics. 5. ed. Oxford: Butterworth-heinemann, 2000. v. 2. 459p.

ZIENKIEWICZ, O.; CHEUNG, Y. The finite element method in structural and continuum mechanics: numerical solution of problems in structural and continuum mechanics. 1. ed. New York: McGrawHill, 1967. 272p. 